\title{
Properties of aerosols and their wet deposition in the arctic spring during ASTAR2004 at Ny-Alesund, Svalbard
}

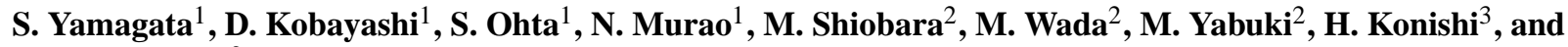 \\ T. Yamanouchi ${ }^{2}$ \\ ${ }^{1}$ Graduate School of Engineering, Hokkaido University, Sapporo, Japan \\ ${ }^{2}$ National Institute of Polar Research, Tokyo, Japan \\ ${ }^{3}$ Osaka Kyoiku University, Osaka, Japan
}

Received: 30 June 2008 - Published in Atmos. Chem. Phys. Discuss.: 25 August 2008

Revised: 5 December 2008 - Accepted: 5 December 2008 - Published: 14 January 2009

\begin{abstract}
During the period of scientific campaign "Arctic Study of Tropospheric Aerosols, Clouds and Radiation 2004" (ASTAR2004), precipitation samples were collected in late spring at Ny-Alesund, Svalbard and their ionic components were analyzed in parallel with the measurement of properties of atmospheric aerosol particles at the same place. Backward trajectory analyses indicated that the air mass above the observatory initially dominated by air masses from the Arctic Ocean, then those from western Siberia and later those from Greenland and the Arctic Ocean. In the measurement period, six precipitation samples were obtained and five of them were analyzed their ionic components by ionchromatography. The concentrations of nss-sulphate in precipitations were between 1.8 and $24.6 \mathrm{ppm}$ from which the scavenging ratio and scavenging coefficients were calculated using the data such as the concentrations of nss-sulphate in aerosol particles, amounts of precipitations, and the heights of precipitations obtained from radar echo data. The scavenging ratio ranged from $1.0 \times 10^{6}$ to $17 \times 10^{6}$ which are comparable values reported in other areas. A detailed comparison between precipitation events and the number concentration of aerosol particles obtained from optical particle counters suggests that the type of precipitations, i.e. rain or snow, significantly affects the number concentrations of aerosol particles.
\end{abstract}

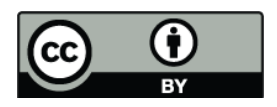

Correspondence to: S. Yamagata (yamagata@eng.hokudai.ac.jp)

\section{Introduction}

Arctic haze is widespread anthropogenic pollution over arctic regions from winter to spring. The major reasons for the generation of arctic haze are considered to be the entrainment of source areas of anthropogenic pollutants into the arctic air mass and the decreased activity of the removal process due to less convective conditions in those seasons. (Shaw and Khalil, 1989 and references therein) Both reasons derive from distinct meteorological conditions in polar areas, i.e. a deficit of solar radiation during the winter season. This situation is clearly illustrated by seasonal variations observed during continuous monitoring of aerosol particles in the arctic region over several years (Shaw, 1995; Quinn et al., 2005; Herber et al., 2002), which show contamination maxima in spring and minima in summer.

Several stations in the arctic region are monitoring the atmospheric environment to assess the anthropogenic influences. Among them, Ny-Alesund is one of the most sophisticated observation sites, where institutions from many countries have established their observatories and they collaborate in international scientific programs, e.g. Arctic Study of Tropospheric Aerosols, Clouds and Radiation 2004 (ASTAR2004). Several studies have reported the properties of aerosol particles in Ny-Alesund. Some of these are intense studies of limited duration (Covert and Heintzenberg, 1993; Lehrer et al., 1997; Nyeki et al., 2005; Teinila et al., 2004; Nishita et al., 2001). However, there are relatively few studies by continuous monitoring that include the data demonstrating seasonal variations in aerosols. One of the

Published by Copernicus Publications on behalf of the European Geosciences Union. 
exceptions is a year-round measurement of aerosol particles for their size distributions and chemical compositions performed by Stroem et al. (2003) on a mountain ridge in NyAlesund. They found that a very strong seasonal variation existed in size distribution patterns and it took only several days for the aerosol type to change from one regime to the other. This change in the size distribution is especially distinct between spring and summer, when the maximum shifts from the submicron region to the nanometer region, i.e. from the accumulation mode to the Aitken mode. They suggest that the change in the size distribution is due to the change in the transport patterns of air masses arriving there.

Heintzenberg et al. (2003) reported high concentrated aerosol loadings in Central Europe and suggested the arrival of arctic haze. The lateral transportation of the arctic haze to the lower latitudes is one of the processes that reduce the aerosol loading in the arctic atmosphere.

According to a recent study by Engvall et al. (2008) the transition from "spring-type" to "summer-type" aerosol occurs almost at the same time every year within a 10-day period including Julian Day (JD) 145. They concluded that transport alone can not explain this transition and indicated the importance of nucleation potential for new particle formation mainly driven by solar radiation.

When the solar radiation returns to the arctic region in spring, it not only accelerates the new particle formation by photochemical reactions but also prompts the atmospheric convections that results in cloud generation (Shiobara et al., 2003) and precipitations (Konishi and Wada, 2005). In general, this precipitation is one of the main mechanisms for removing aerosol particles not by dilution with clean air, but by complete removal from the atmosphere through their transportation down to the ground. Before precipitation reaches the ground, two processes are considered to exist through which aerosol particles are removed from the atmosphere, i.e. rain-out and wash-out processes. The former process removes aerosol particles at the altitude of cloud generation, where they act as cloud condensation nuclei, while the latter process is due to the removal of aerosol particles by precipitation particles, i.e. raindrops, snowflakes etc., between cloud bases and the ground during their transport. Both of removal processes are called wet deposition, as a whole, while direct deposition of aerosol particles on the ground surface without precipitation is referred to as dry deposition.

Although seasonal variations in aerosol particles in $\mathrm{Ny}-$ Alesund were shown, the significance of the dilution and deposition processes are not clear. To evaluate one of the processes, i.e. deposition, we have to obtain the deposition rate of aerosol particles in the arctic region. Until now there have been only a few studies on the direct measurements of precipitations from the viewpoint of deposition in the arctic (Wada and Igarashi, 1998).

In this present study, measurement of both the concentration of aerosol particles and the amount of ionic components in precipitations during the clean-up season for arctic haze were performed at the international research site at $\mathrm{Ny}-$ Alesund, Svalbard, to estimate the role of precipitations in aerosol removal by deposition.

\section{Method}

Aerosol measurement and precipitation sampling were performed at "Rabben", the research observatory of the National Institute of Polar Research (NIPR) of Japan, in Ny-Alesund, Svalbard ( $78^{\circ} 56^{\prime} \mathrm{N}, 11^{\circ} 52^{\prime} \mathrm{E}, 40 \mathrm{~m}$ a.s.l.), from 133JD (12 May) to 168JD (16 June) of 2004 as part of the research campaign ASTAR2004. The observatory is located just beside the air strip of Ny-Alesund and faces northeast towards the Kongsfjord.

All aerosol measurements were performed in a small shed at the observatory next to the main building. Aerosol particles from an inlet $3 \mathrm{~m}$ above the ground were distributed to each instrument through a stainless tube $10 \mathrm{~cm}$ in diameter. Aerosol particles for chemical analyses were collected without any size segregation using a filter (Sumitomo Electric, FP-500) continuously for $24 \mathrm{~h}$ at a flow rate of $28 \mathrm{~L} / \mathrm{min}$. There are seven exceptional samples (138139, 144-145, 149-150, 155-156, 161-162, 163-164, 165166JD) for which aerosol particles were collected for $48 \mathrm{~h}$ using filters to obtain sufficient amounts of them or simply for operational reasons. The sampling filters were exchanged at 09:00 local time (LT). Occasionally, the sampling was interrupted for several hours to prevent local contaminations by exhaust gases from aircrafts and snow removal vehicles. The sample filters were stored in a refrigerator and brought back to the laboratory at Hokkaido University, and then their ionic components were analyzed using an ion chromatograph (Dionex DX500, AS12A, CS12).

Two optical particle counters (OPCs) were installed at the same monitoring site to measure the number concentrations of aerosol particles. One OPC (Rion, KC-22B) measured the concentration of particles with diameters larger than 0.08 , $0.1,0.2$ and 0.3 um, while the other OPC (Rion, KC-01D) measured those larger than $0.3,0.5,1.0,3.0$ and $5.0 \mathrm{um}$.

Scattering and absorption coefficients of aerosol particles were continuously monitored using an integrating nephelometer (IN, TSI 3563) and an absorption photometer (Radiance Research, PSAP), respectively. All of the instruments, i.e. OPCs, IN and PSAP, were operated at the same site using the same inlet tube as for the filter sampling.

A precipitation collector, a stainless-steel funnel with a diameter of $24 \mathrm{~cm}$ equipped with a plastic tube used as a container for collecting precipitation, was settled on the roof of the main building of the observatory. Ion-exchanged water was used to cleanse and collect the deposited substances into the plastic tube. After the collection of two samples of dry deposition on the first two days of the campaign, the plastic tubes were exchanged at 09:00 LT only in case of precipitation. The volume of each obtained precipitation sample in the 


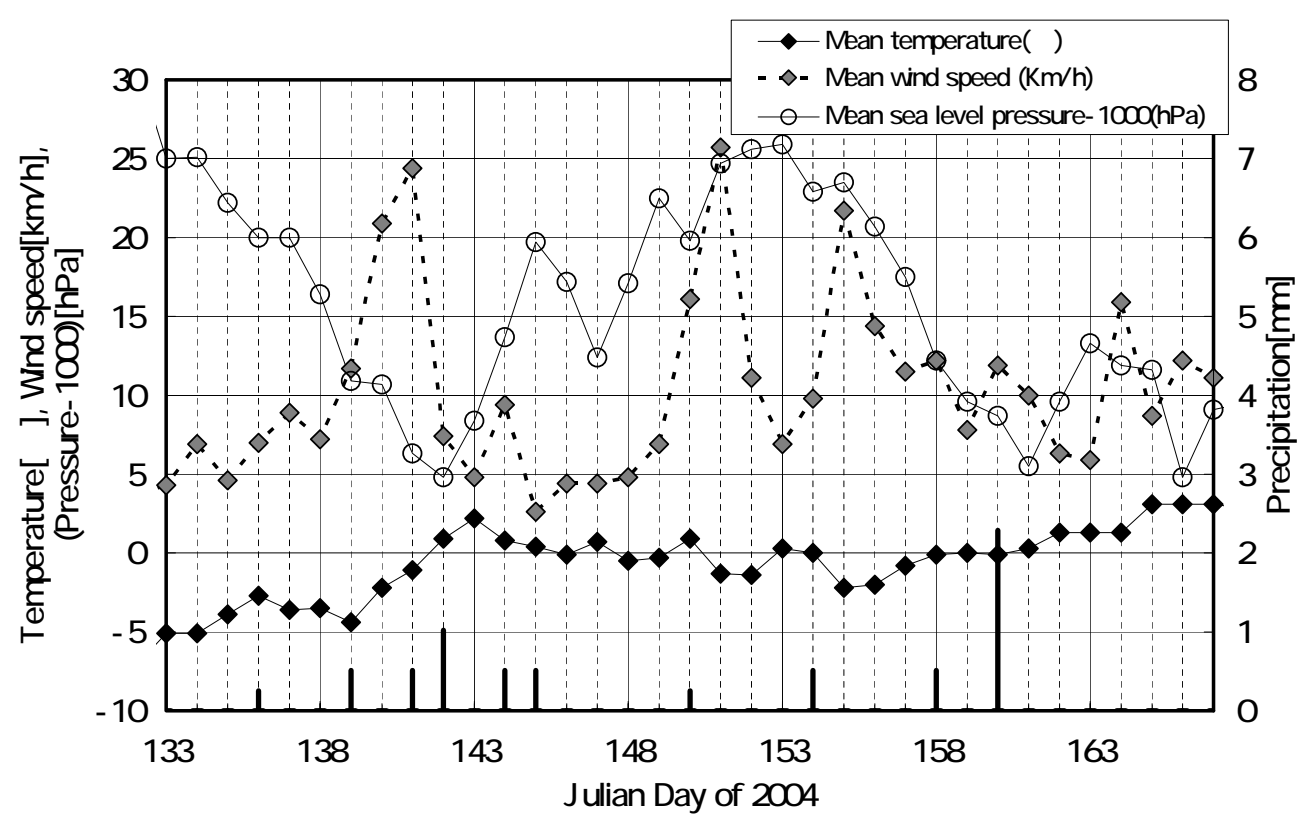

Fig. 1. Meteorological conditions at Ny-Alesund during ASTAR2004 campaign.

plastic tube was measured. Each sample was filtered using a PTFE filter with 0.2-um pores (Advantec, DISMIC-13HP) and then stored in a refrigerator at the observatory, similar to aerosol samples.

The amount of precipitation was monitored using a Precipitation Occurrence Sensor System (POSS), a 10.525-GHz bistatic Doppler radar, which measured the amount of precipitation every $1 \mathrm{~min}$. Data from the POSS include the existence of a precipitation event, the type of precipitations and the relative amount of precipitations. However, the daily amounts of total precipitation were measured using the precipitation collector mentioned above, and did not always coincident exactly with POSS data.

X-band vertically pointing radar (Wavelength: $3.2 \mathrm{~cm}$, Antenna diameter: $2.4 \mathrm{~m}$, Peak power: $40 \mathrm{~kW}$ ), which was installed at the same observational site (Wada and Konishi, 1998) measured the radar reflectivity every $10 \mathrm{~s}$ up to $6.4 \mathrm{~km}$ with a 50-m resolution. Echo data from the precipitation was used to estimate the top of the air column in which aerosol particles were scavenged by precipitation.

\section{Results and discussion}

\subsection{Meteorological conditions during the campaign}

Figure 1 shows the meteorological parameters, i.e., air temperature, wind speed, barometric pressure and amount of precipitation, at Ny-Alesund during the campaign ( $\mathrm{Tu}-$ tiempo.net). Average air temperature varied from -6 to $+2^{\circ} \mathrm{C}$ which resulted in a change in the precipitation type on the ground, i.e. rain and snow, during the campaign. Precip- itation occurred intermittently during the period, which was sufficient for collection using the precipitation sampler used here.

Five-day backward trajectories (Murao et al., 1997) from the height of $925 \mathrm{hPa}$ at the sampling site are shown in Fig. 2, which indicates that the air mass above the sampling site was initially influenced by the Arctic Ocean in the days between 133 and 137JD. Then, from 139 to 145JD, air masses from western Siberia dominated, which may have been contaminated by anthropogenic sources such as sulphur dioxide from the smelting industry in Norilsk (Ohta et al., 1995). After several day with air mass around Svalbard archipelago due to stable barometric conditions, air masses from west including Greenland dominated after 151JD. From 157 to 163JD, air masses were influenced by the Arctic Ocean again, and at the last period of the campaign, around 165JD, air masses from Barents Sea were predominant.

According to the meteorological data at $\mathrm{Ny}$-Alesund ( $\mathrm{Tu}-$ tiempo.net) in 2004 heavy precipitation continued several days around 70JD when solar radiation returned to the Svalbard archipelago and 90JD. These precipitation events may have removed some arctic haze before the campaign started at $133 \mathrm{JD}$. Although relatively heavy precipitations generally occur at Ny-Alesund in early spring, the maxima of aerosol loading in terms of optical thickness at Ny-Alesund are observed at the beginning of May (Herber et al., 2002) around 125JD.

\subsection{Properties of aerosol particles during the the campaign}

Figure 3 illustrates the time series of several aerosol parameters, i.e., the concentrations of major ionic components, 

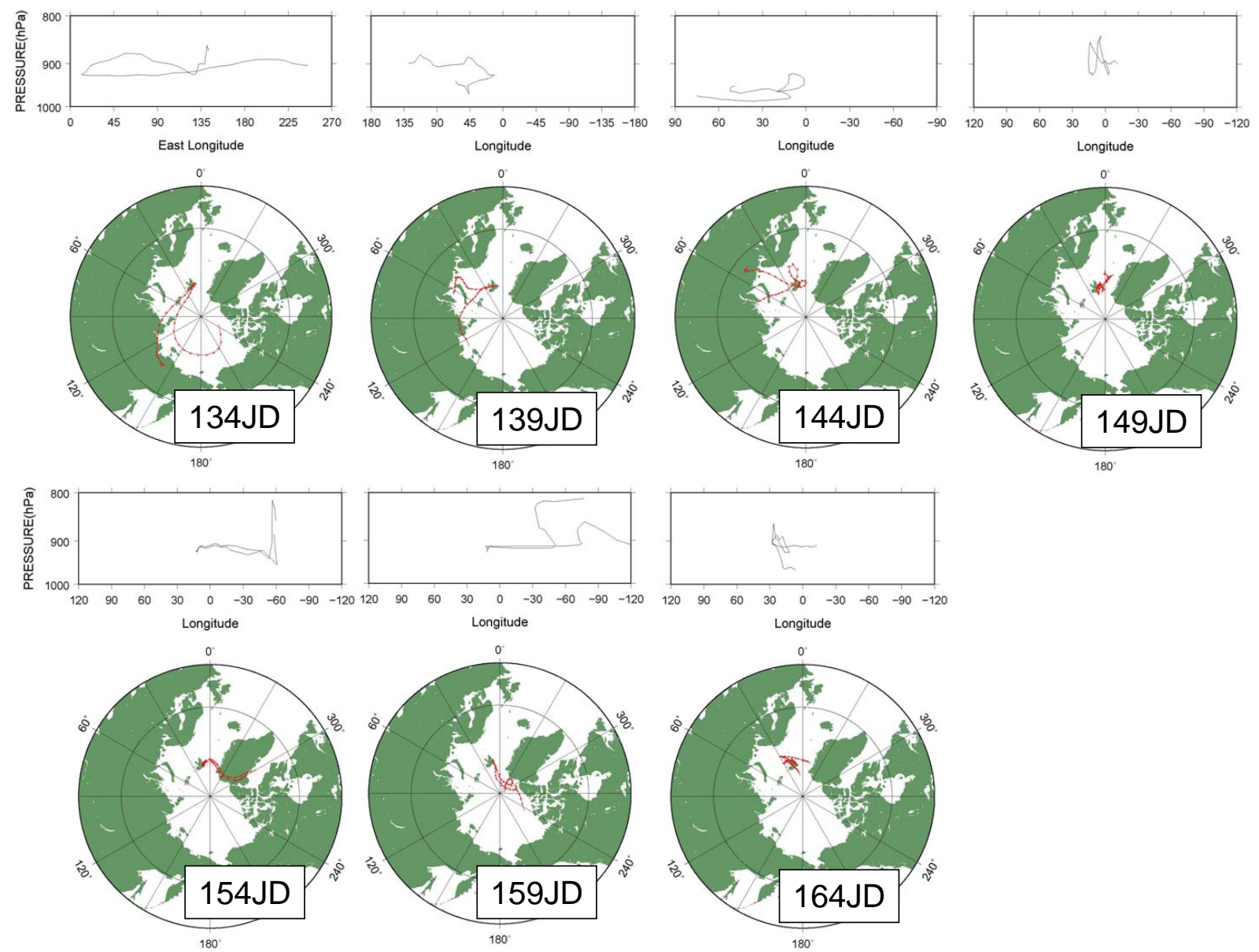

Fig. 2. Five-day back trajectories from Ny-Alesund during ASTAR2004 campaign. Daily panels include two trajectories which originate Ny-Alesund at 02:00 and 14:00 LT.

scattering and absorption coefficients measured by IN and PSAP, and number concentrations measured using the OPCs. All clearly demonstrate the gradual decrease in aerosol concentrations in this period, with some daily fluctuations.

Among all the observed ionic components sulphate dominates as reported previously (Heintzenberg et al., 1981; Covert and Heintzenberg, 1993; Lehrer et al., 1997). At the beginning of the campaign the air mass from the Arctic Ocean contained 2-7 $\left[\mathrm{ug} / \mathrm{m}^{3}\right]$ of ionic component in aerosols, which decreased to about $0.5\left[\mathrm{ug} / \mathrm{m}^{3}\right]$ at the end of the campaign. Although some air masses in the first period of this campaign, i.e., from 139 to $145 \mathrm{JD}$, may have been influenced directly by the anthropogenic sources in western Siberia, the observed air masses during this campaign mostly originated from the Arctic Ocean and may have reflected the trends of the air masses in that area during this period.

Scattering coefficients also indicate the decrease in aerosols, which were $1 \times 10^{-5}\left[\mathrm{~m}^{-1}\right]$ at the beginning of the campaign and became around half that value at the end. Although the decrease in absorption coefficients is not as distinct as those observed in ionic components and scatter- ing coefficients, the absorption coefficients took relatively a higher value in the first period of the campaign than later.

Particle number concentrations, shown in the bottom panel of Fig. 3 provide further evidence of similar decreasing trends of aerosol loading in $\mathrm{Ny}$-Alesund during the campaign.

Although all the trends in aerosol particles mentioned above may be explained by the temporal meteorological conditions, it should be noted that the time period of this campaign included the period of the aerosol transition from spring-type to summer-type, as indicated by Engvall et al. (2008). Therefore, it is reasonable to regard the decrease in aerosol loading in this study as being partly a reflection of the aerosol transition processes occurring in the arctic region around this time period of the year.

The only exception of this aerosol transition is in the number concentration of particles with the diameter larger than 1.0 um, which remained constant throughout the campaign. The correlations between the number concentrations of each size region $\left(R^{2}=0.64\right.$ between particles $>0.1 \mathrm{um}$ and those $>0.3 \mathrm{um} ; R^{2}=0.01$ between particles $>0.1 \mathrm{um}$ and those 
$>1.0 \mathrm{um}$ ) indicate that the particles larger than $1.0 \mathrm{um}$ may have had a different source from that of smaller particles. Sea-salt particles originating from the ocean may explain such phenomena. Support for this explanation can be seen in Fig. 3, where concentrations of sea-salt's components, $\mathrm{Na}$ and $\mathrm{Cl}$ synchronized with the number concentration of particles larger than 1.0 um on 151 and 158JD.

Concerning the properties of aerosol, 151JD is a noteworthy day during the campaign. The major components changed from sulphate to sea-salt and the number concentration of particles larger than $1.0 \mathrm{um}$ showed the highest value. According to the meteorological data, the strongest wind $(7 \mathrm{~m} / \mathrm{s}$ mean) was observed on this day as shown in Fig. 1, which may have caused a lot of particle production from the ocean around the Svalbard archipelago. Teinila et al. (2004) reported that sea-salt components were the most abundant ions in the super-micron size range. From these considerations, it is appropriate to recognize that sea-salt particles existed mainly in this size range.

\subsection{Precipitation in Ny-Alesund during the campaign}

\subsubsection{Physical properties of precipitation}

We obtained six precipitation samples and five of them were analyzed as shown in Table 1. These samples were collected from 09:00 LT to the same time on the following day. For example, the precipitation that started in the afternoon of 144JD continued until the following day. After the exchange of the sampler, however, the amount of precipitation was very small to be collected by the sampler. Therefore, no precipitation sample was collected on 145JD.

Figure 4 compares the results from the POSS system and $\mathrm{X}$-band radar echoes on 144JD. Due to the working principle of the radar, we have no data up to $500 \mathrm{~m}$ from the ground surface. In the time period of 00:00-03:00 LT and after 21:00 LT, radar echoes reached to the bottom of the detection limit and the POSS reported precipitation. The results from these two instruments agreed well which may be because the measurement principles are the same, i.e. the detection of precipitation by the intensity of scattered radio waves emitted upward from the ground surface.

Although the amount of precipitations collected by the sampler corresponded to the integrated POSS reports in part, the degree of coincidence was lower than that between POSS data and radar echoes. Several causes contribute the differences between them. Measurements with radio waves targeted the droplets above the ground, while the precipitation sampler collected precipitation particles on the ground. This caused a difference in the amount of precipitation especially when the wind speed was high and precipitation particles were blown horizontally as they fell. Another reason for the discrepancy may be the location of the instruments; the precipitation sampler was about $10 \mathrm{~m}$ distant from the POSS, while the distance between the POSS and the radar was less.
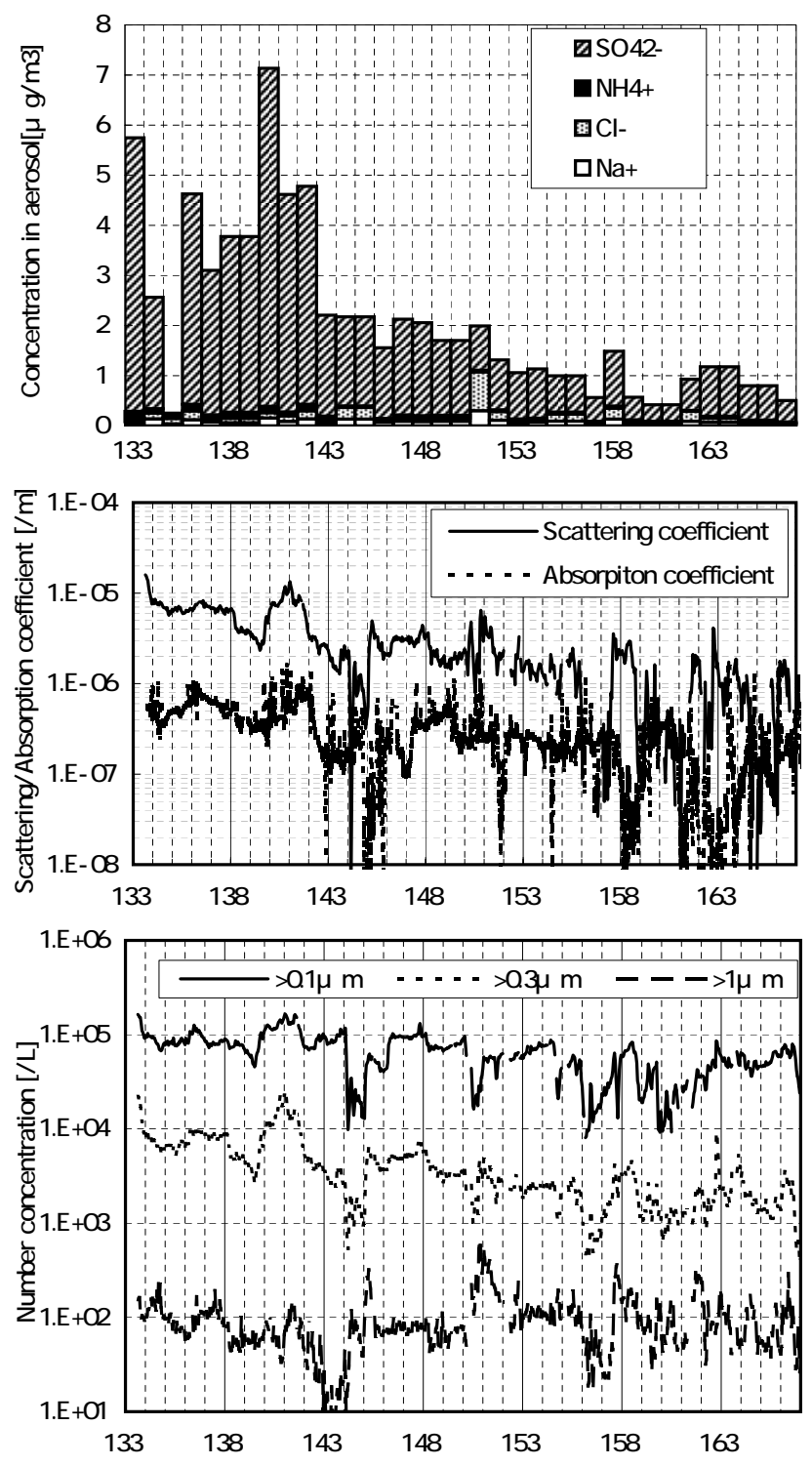

Fig. 3. Aerosol properties at Ny-Alesund. Ionic components (top); Optical scattering coefficient and absorption coefficient (middle); Particle number concentrations (bottom). Aerosol sulphate concentration on 135JD is missing.

In this study, the amount of precipitations obtained by the sampler will be used unless otherwise specified.

\subsection{Chemical species in precipitation}

The amounts of dry deposition measured at the beginning of the campaign show that they were much lower (Na: $40 \mathrm{ug} / \mathrm{day} / \mathrm{m}^{2} ; \mathrm{Cl}: 30 \mathrm{ug} / \mathrm{day} / \mathrm{m}^{2} ; \mathrm{SO} 4: 2 \mathrm{ug} / \mathrm{day} / \mathrm{m}^{2}$ ) than the amounts of wet deposition. Therefore, in the following parts of this study, "wet deposition" refers to the total deposition including dry deposition, which was not separable during precipitation sampling in this study. 
Table 1. Concentrations of ionic components in precipitation samples.

\begin{tabular}{|c|c|c|c|c|c|c|c|c|c|c|c|c|c|}
\hline \multirow[b]{2}{*}{ ID } & \multirow{2}{*}{$\begin{array}{c}\text { Julian Day of } \\
2004\end{array}$} & \multicolumn{2}{|c|}{ Precipitation } & \multirow[b]{2}{*}{$\mathrm{Na}$} & \multirow[b]{2}{*}{ NH4 } & \multirow[b]{2}{*}{$\mathrm{K}$} & \multirow[b]{2}{*}{$\mathrm{Mg}$} & \multicolumn{2}{|c|}{$\begin{array}{c}\text { Concentration } \\
{[\mathrm{mg} / \mathrm{L}]}\end{array}$} & \multirow[b]{2}{*}{$\mathrm{NO}_{2}$} & \multirow[b]{2}{*}{$\mathrm{NO}_{3}$} & \multirow[b]{2}{*}{$\mathrm{SO}_{4}$} & \multirow[b]{2}{*}{ nss-SO } \\
\hline & & amount $[\mathrm{mm}]$ & type & & & & & $\mathrm{Ca}$ & $\mathrm{Cl}$ & & & & \\
\hline$\# 1$ & 142 & 0.66 & Rain & 29.5 & 0.3 & 7.8 & 6.3 & 7.1 & 44.9 & 0.5 & 9.0 & 20.4 & 13.0 \\
\hline$\# 2$ & 143 & 1.35 & Rain $(\text { Snow })^{*}$ & 40.4 & 0.5 & 13.8 & 8.1 & 7.3 & 66.3 & 2.3 & 7.6 & 34.7 & 24.6 \\
\hline$\# 3$ & 144 & 0.84 & Rain & 0.5 & 0.1 & 0.6 & 0.2 & 0.4 & 0.4 & ND & 0.5 & 1.9 & 1.8 \\
\hline$\# 4$ & 153 & 0.75 & Sleet & 5.9 & 0.5 & 5 & 1.8 & 3.2 & 8.3 & ND & 3.5 & 8.3 & 6.8 \\
\hline$\# 5$ & 160 & 1.55 & Snow & 4.6 & 0.5 & 3.2 & ND & ND & 6.8 & ND & 1.7 & 6.8 & 5.6 \\
\hline$\# 6$ & $161^{* *}$ & 0.18 & Snow & - & - & - & - & - & - & - & - & - & - \\
\hline
\end{tabular}

*type in parenthes indicates the data from POSS

${ }^{* *}$ Concentrations were not obtained due to an error during sample operation

144JD
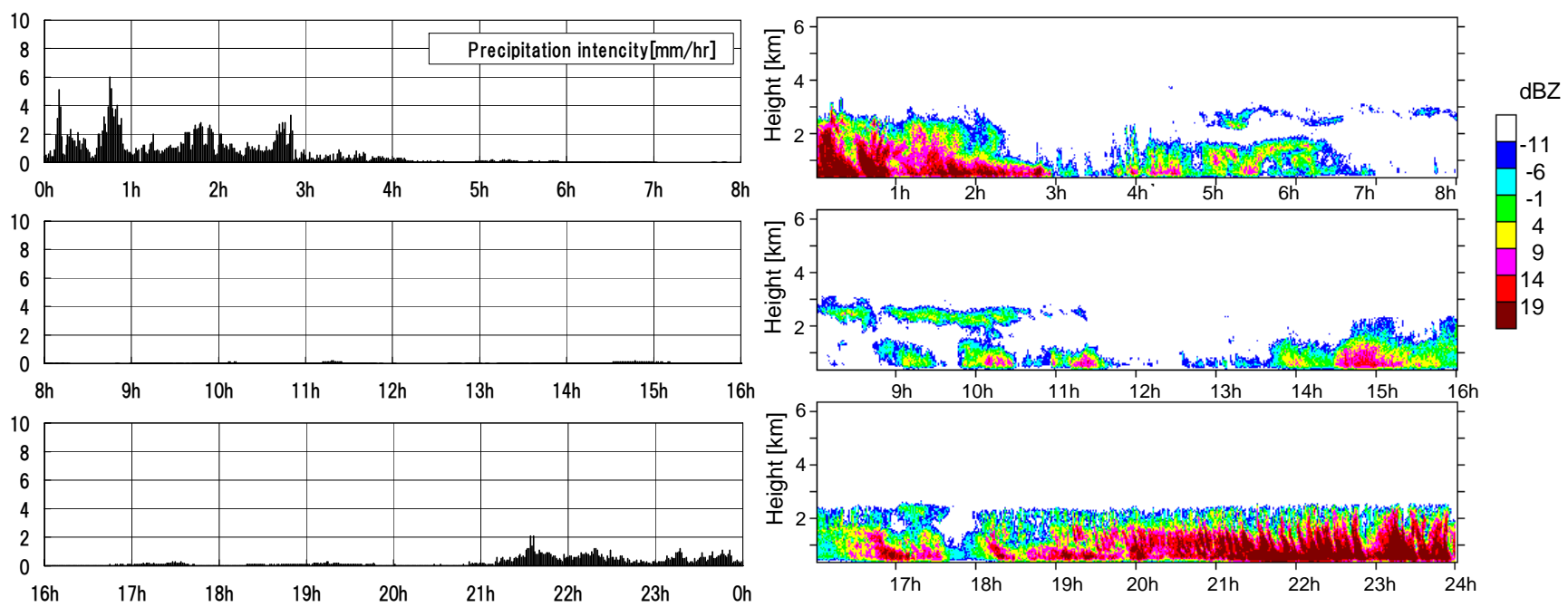

Fig. 4. Example of the comparison between precipitation reports by POSS (left) and radar echo (right).

The concentrations of chemical species in each precipitation event are shown in Table 1. The major ionic components were sodium and chloride derived from sea-salt, sulphate, and nitrate. The concentrations of sea-salt were extremely high in precipitation samples obtained on 142 and 143JD, although the concentrations of sea-salt in aerosol particles were not as high on both days. The POSS reported that the intensities of precipitations were the strongest of the campaign on these days, even exceeding $5 \mathrm{~mm} / \mathrm{h}$, while intensities on other days were at most $1 \mathrm{~mm} / \mathrm{h}$. Chate et al. (2007) calculated the scavenging coefficients of $\mathrm{NaCl}$ and showed that the stronger the rain fall intensity, the more $\mathrm{NaCl}$ was scavenged by rain. They also pointed out that particles larger than 3 um are significantly affected by the rainfall intensity. Therefore, the high concentrations of sea-salt in precipitations on 142 and 143JD can be explained by strong precipitation on these days. The sudden decrease in the number concentration of super-micron particles observed at the same time period (Fig. 3, bottom panel) also supports the belief that strong precipitations washed out the sea-salt particles with diameter larger than $1.0 \mathrm{um}$.

The major component of precipitation after sea-salt was sulphate which contributed $20-60 \%$ of the total ions in the precipitation samples and was the major ionic component in aerosol particles. The concentrations of non-sea-salt (nss) sulphate (Ohta and Okita, 1990) in precipitation during the campaign were in the range of $1.8-24.6 \mathrm{ppm}$. The concentrations of sulphate in samples \#1 and \#2 are higher than those in the other samples in this study. These two highly concentrated samples may have been influenced by the source region of western Siberia, as suggested by back trajectory analyses. Except these two samples, the nss-sulphate concentrations in precipitations are comparable to or are relatively higher than those reported previously (Wada and Igarashi, 1998). The higher values in this study can be attributed in part to the different sampling seasons of the precipitation samples. In general, there are relatively frequent and heavy precipitation events in early spring in this area. When 
Table 2. Concentrations of ionic components in precipitation samples.

\begin{tabular}{|c|c|c|c|c|c|c|c|c|c|c|c|}
\hline \multirow[b]{2}{*}{ ID } & \multirow[b]{2}{*}{$\begin{array}{c}\text { Julian } \\
\text { Day of } \\
2004\end{array}$} & \multirow[b]{2}{*}{$\begin{array}{c}\text { Temperature } \\
{\left[{ }^{\circ} \mathrm{C}\right]}\end{array}$} & \multicolumn{6}{|c|}{ Precipitation } & \multirow{2}{*}{$\begin{array}{c}\text { Aerosol } \\
C_{\text {aerosol }\left(\mathrm{SO}_{4}^{2-}\right)} \\
{\left[\mathrm{ug} / \mathrm{m}^{3}\right]}\end{array}$} & \multicolumn{2}{|c|}{ Wet deposition parameters } \\
\hline & & & $\begin{array}{l}\text { Duration* } \\
\text { [min] }\end{array}$ & $\begin{array}{l}\text { Amount** } \\
{[\mathrm{mm}]}\end{array}$ & $\begin{array}{c}\text { Intensity } \\
{[\mathrm{mm} / \mathrm{s}]}\end{array}$ & $\begin{array}{l}\text { Height }^{\#} \\
{[\mathrm{~m}]}\end{array}$ & Type & $\begin{array}{c}{ }^{C} \text { precipitation }\left(\mathrm{SO}_{4}^{2-}\right) \\
{[\mathrm{mg} / \mathrm{L}]}\end{array}$ & & $\begin{array}{c}\text { Scavenging ratio }(\mathrm{H}) \\
\left(={ }^{C} \text { precipiation } /{ }^{C} \text { aerosol } \times 10^{6}\right)\end{array}$ & $\begin{array}{c}\text { Layer-average } \\
\text { scavenging coefficient } \\
(=\mathrm{H} \times \text { Intensity/Height })\end{array}$ \\
\hline$\# 1$ & 142 & $2 \sim 9$ & 124 & 0.66 & $8.9 \mathrm{E}-05$ & 3500 & Rain & 13.0 & 4.35 & $3.0 \mathrm{E}+06$ & 7.6E-05 \\
\hline$\# 2$ & 143 & $-1 \sim 13$ & 485 & 1.35 & 4.7E-05 & 2500 & Rain (Snow) ${ }^{\# \#}$ & 24.6 & 2.02 & $1.2 \mathrm{E}+07$ & $2.3 \mathrm{E}-04$ \\
\hline \#3 & 144 & $0 \sim 6$ & 658 & 0.84 & 2.2E- 05 & 2300 & Rain & 1.8 & 1.78 & $1.0 \mathrm{E}+06$ & $9.8 \mathrm{E}-06$ \\
\hline \#4 & 153 & $0 \sim 6$ & 150 & 0.75 & $8.3 \mathrm{E}-05$ & 2800 & Sleet & 6.8 & 0.92 & 7.4E+06 & $2.2 \mathrm{E}-04$ \\
\hline$\# 5$ & 160 & $-1 \sim 5$ & 670 & 1.55 & $3.9 \mathrm{E}-05$ & 2600 & Snow & 5.6 & 0.33 & $1.7 \mathrm{E}+07$ & $2.5 \mathrm{E}-04$ \\
\hline
\end{tabular}

*Integrated time in minutes of the POSS data for precipitation intensity stronger than $0.1 \mathrm{~mm} / \mathrm{h}\left(=2.8 \times 10^{-5} \mathrm{~mm} / \mathrm{s}\right)$

** Calculated from the amount of precipitations by the collector

${ }^{\#}$ Estimated from the data from radar

${ }^{\# \#}$ Form in parenthes indicates the data from POSS

an amount of precipitation at a time increases, scavenged ionic components are diluted. Therefore their concentrations in precipitation samples are lowered even if highly concentrated pollutants in arctic haze are collected in the precipitation sample. During this campaign, the amounts of precipitations were much lower than those reported in early spring. The lack of a dilution process resulted in the relatively high concentrations of each component in precipitation samples, even though the aerosol concentration was lower than those in early spring.

For samples \#1 and \#2 nss-sulphates concentrations in precipitations were very high. On these days the air mass above the observatory had passed over source regions such as Scandinavia and western Siberia. The sulphate concentration in sample \#3 is low, although it precipitated from an air mass similar to the one that produced precipitation samples \#1 and \#2. From 142 to $144 \mathrm{JD}$, precipitation continued and precipitation samples were obtained every day. In usual the concentrations of chemical species in precipitations are higher at the beginning of precipitation events and decreases with time due to the wash-out of aerosol particles in the atmosphere. When we compare their concentrations of ionic components in precipitation for these three days, it is clear that the concentrations on 143JD are higher than those on 142JD. According to POSS reports, the precipitation on 142JD continued only several hours during 15:00 LT to 18:00 LT. From this, we can estimate that the precipitation on 142JD occurred over only a limited area, and the air mass arriving at Ny-Alesund on 143JD had been incompletely washed-out by the precipitation. In contrast, the concentrations of ionic components on 144JD decreased from those on 143JD. The POSS reports indicated that precipitation continued intermittently on these two days. It may have been a typical process of precipitation of washing out aerosol particles in the atmosphere.

The precipitation type on these three days must be also noted. The temperature during precipitations on 142JD was between +2 and $+9^{\circ} \mathrm{C}$ which resulted in rain on the ground. It became colder on the following day, resulting temperatures below zero, and the precipitation type changed from rain to snow occasionally.
Murakami et al. (1983) reported, through the measurement of chemical species both at the bottom of the cloud base and on the ground surface, that the wash-out efficiency of snow was several times higher than that of rain. The change of precipitation type may also have influenced the time sequences of the concentrations of chemical species in Table 2 on these three days.

3.5 Relationship between aerosol concentrations and pre-
cipitation concentrations

\subsubsection{Scavenging coefficient of nss-sulphate}

The removal process of aerosol particles by precipitations is evaluated by the scavenging coefficient defined as follows

$d C_{\text {aerosol }} / d t=-k_{\text {local }} C_{\text {aerosol }}$

where $C_{\text {aerosol }}$ is the concentration of aerosol components, and $k_{\text {local }}$ is the scavenging coefficient defined for specific conditions. As mentioned above, aerosol removal by precipitation consists of two main paths, the rain-out and washout processes. However, it is not so easy to collect cloud droplets before they start to fall. Therefore, the typical practice adopted in this study is to measure the concentrations of ionic components in the precipitations collected on the ground surface and to treat the removal process as a whole, including rain-out and wash-out. If we make two hypotheses, such as the concentrations of ionic components in aerosol particles below the cloud base are constant and their removal processes by precipitating particles, rain drops, snowflakes etc. proceed uniformly at each altitude, the layer-averaged scavenging coefficient (Okita et al., 1996) is expressed as follows

$k=H \times p / h$

where $p$ is precipitation intensity $[\mathrm{mm} / \mathrm{s}]$, and the $h$ is the height $[\mathrm{m}]$ of a sweeping volume of precipitation in the air, which is estimated from the height of the X-band echo in this study. Scavenging ratio $H$ in Eq. (2) is defined by Eq. (3), 


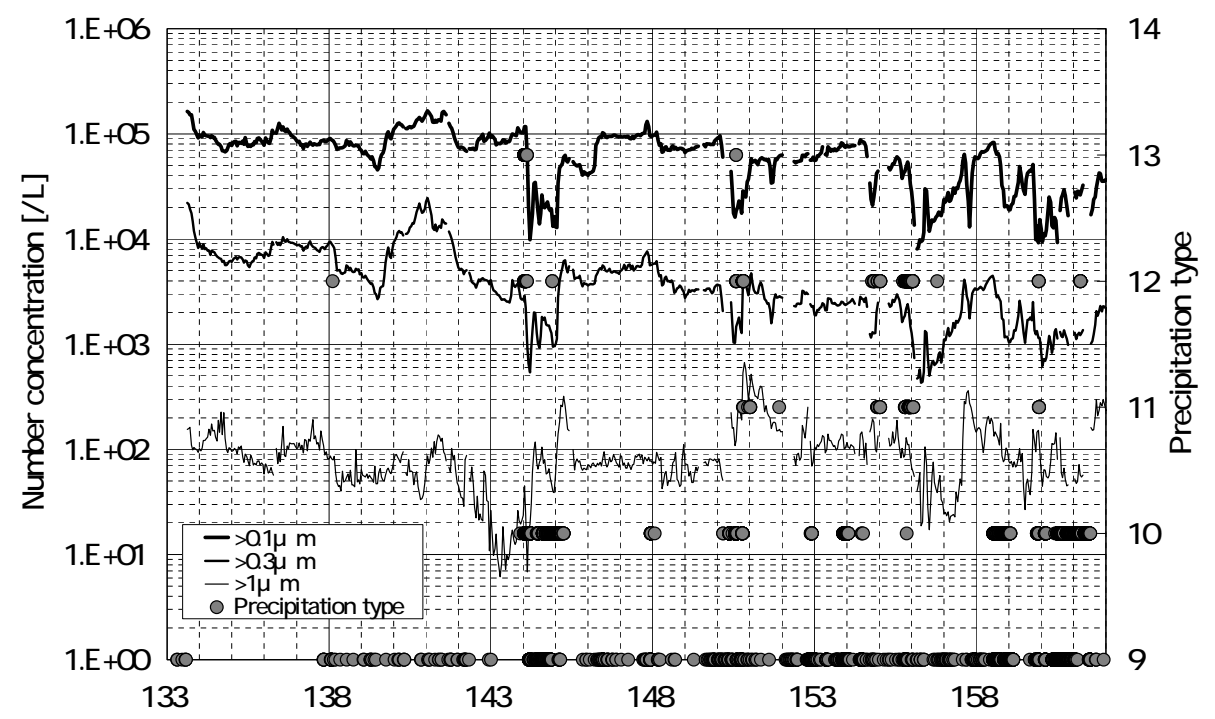

Fig. 5. Influence of snow falls on the time variations of particle number concentrations of aerosols.

which is a ratio of the concentration of certain substances in precipitation to its concentration in the aerosol particles.

$H=C_{\text {precipitation }} / C_{\text {aerosol }}$

These parameters for nss-sulphate are shown in Table 2 with data used for calculation. The scavenging ratios of sulphate ranged between $1.0 \times 10^{6}$ and $17.0 \times 10^{6}$ which are comparable to values as reported for other sites (KasperGiebl, 1999; Davis et al., 1997). Relatively lower $k$ values are obtained for 142 and 144JD, when the POSS consistently reported rain as the precipitation type.

The scavenging ratio for sea-salt ranged between $2.2 \times 10^{3}$ and $7.7 \times 10^{5}$, which are much smaller than the values for nss-sulphate. This may be explained by the difference in the vertical profiles of the two species. The concentration of sea-salt aerosols is higher at lower altitudes because they are emitted from the open ocean, while nss-sulphate is formed in the atmosphere and dispersed at a rather high altitude than sea-salt aerosol. For the calculation of the scavenging ratio in this study, aerosol concentrations only on the ground were available, which gives a smaller $H$ value for the species concentrated near the ground such as sea-salt.

\subsubsection{Changes in aerosol particle number concentrations} during precipitation events

Besides the daily averaged values of the scavenging ratio and scavenging coefficient for sulphate in aerosol particles, a comparison between the time variations of particle number concentrations from optical particle counters and those of POSS precipitation data gives some insights into the influence of wet deposition on the number concentration of aerosol particles.
Figure 5 shows number concentrations of particles with diameter larger than $0.1,0.3$ and 1.0 um during the days from 133 to 161JD when POSS data are available. Although there are always fluctuations in their time variation, there appear to be baselines about which data fluctuate. The baselines for particles larger than 0.1 and $0.3 \mathrm{um}$ are $1 \times 10^{5}[/ \mathrm{L}]$ and $2-$ $10 \times 10^{3}[/ \mathrm{L}]$, respectively. Both show a tendency to decrease from the beginning to the end of the campaign, as mentioned above.

When the time variations of number concentrations are examined in detail there are several periods during which the number concentration decreased far beyond these base lines. One such lower-concentration period appeared on 144JD. In this period, the number of particles with diameter larger than $0.1 \mathrm{um}$ decreased down to $2 \times 10^{4}[/ \mathrm{L}]$, which is much less than those during other precipitation events. The POSS information indicates that the air temperature decreased down to the freezing point and the precipitation type changed from rain to snow at the beginning of 144JD.

As mentioned above, Murakami et al. (1983) pointed out the difference in wash-out efficiency between snow and rain. They concluded that the snow particles were several times more efficient as scavengers than the rain drops from the view point of the mass of aerosol particles collected by unit mass of precipitation.

Extreme decreases in aerosol particles were also observed in other time periods, i.e. $150,154,156,158,159,160$ and 161JD. All of these days are characterized by the possible snowfall events reported by the POSS. In Fig. 5 snowfall events are represented by grey circles. POSS reports precipitation type $S$, when it detects precipitation and the dew point is below $-1^{\circ} \mathrm{C}$. Precipitation type $P$ corresponds to the dew points between -1 and $+1^{\circ} \mathrm{C}$, which is also regarded as snowfall in this study. Each sign is further categorized into 
four levels according to their intensity, i.e. very light " - -": light "-": moderate " ": and heavy "+". In Fig. 5 larger precipitation-type values are assigned to snow; 13 to $S: 12$ to $S-: 11$ to $S--$. Smaller numbers, i.e. 10 and 9 , are assigned to $P-$ and $P--$, respectively.

Although the sudden decrease in the number concentrations of aerosol particles can also be explained by the exchanges of air mass occurring concurrently with snowfall events, it is more probable that falling snowflakes scavenge the aerosol particles close to the ground surface effectively enough such that the number concentration of aerosol particles drastically decreased. Considering the vertical profiles of the air temperature, i.e. lower temperature at higher altitudes, it is reasonalbe to believe that the aerosol particles high above are scavenged effectively and transported downwards by snowflakes even if the type of precipitation on the ground is rain. In these conditions, the number concentrations of aerosol particles at higher altitudes should decrease due to the effective scavenging by snowflakes, while the number concentrations of aerosol particles at lower altitudes remain at certain levels.

To obtain the conclusive results for the role of wet deposition on the removal of arctic hazes from the atmosphere, it is necessary to monitor the concentrations of both wet deposition and aerosol particles from previous periods including the period of arctic haze.

\section{Summary}

During the ASTAR2004 campaign, the ground-based measurements for aerosol particles and precipitations were performed at Rabben Observatory in Ny-Alesund, Svalbard. During the campaign the aerosol loading at Ny-Alesund decreased partly due to the aerosol transition from "springtype" to "summer-type". From the concentration of nsssulphate in precipitations the scavenging ratio and coefficients were calculated resulting in values comparable to those reported previously. Effective scavenging by snow is indicated by the comparison of time variations of particle number concentrations and POSS reports.

Acknowledgements. This study was supported by Grant-in Aid (No. 16253001) from the Ministry of Education, Culture, Sports, Science, and Technology of Japan.

Edited by: M. Wendisch

\section{References}

Covert, D. and Heingtzenberg, J.: Size distributions and chemical properties of aerosol at NyAlesund, Svalbard, Atmos. Environ., 27A, 2989-2997, 1993.

Chate, D. M., Ali, K., Momin, G. A., Rao, P. S. P., Praveen, P. S., Safai, P. D., and Devara, P. C. S.: Scavenging of sea-salt aerosols by rain events over Arabian Sea during ARMEX, Atmos. Environ., 41, 6739-6744, 2007.
Davis, W. E., Thorp, J. M., and Lee, R. N.: Variability of $\mathrm{SO}_{4}^{2-}$, Total Sulfate, $\mathrm{NO}_{3}^{-}$, and Total Nitrate Scavenging Ratios for the Frontal Boundary Study, J. Appl. Meteorol., 36, 792-800, 1997.

Engvall, A.-C., Krejci, R., Ström, J., Treffeisen, R., Scheele, R., Hermansen, O., and Paatero, J.: Changes in aerosol properties during spring-summer period in the Arctic troposphere, Atmos. Chem. Phys., 8, 445-462, 2008,

http://www.atmos-chem-phys.net/8/445/2008/.

Heintzenberg, J., Hansson, H.-C., and Lannefors, H.: The chemical composition of arctic hazeat Ny-Alesund, Spitsbergen, Tellus, 33, 162-171, 1981.

Heintzenberg, J., Tuch, T., Wehner, B., Wiedensohler, A., Wex, H., Ansmann, A., Mattis, I., Mueller, D., Wendisch, M., Eckhardt, S., and Stohl, A.: Arctic haze over Central Europe, Tellus, 55B, 796-807, 2003.

Herber, A., Thomason, L. W., Gernandt, H., Leiterer, U., Nagel, D., Schulz, K.-H., Kaptur, J., Albrecht, T., and Notholt, J.: Continuous day and night aerosol optical depth observations in the arctic between 1991 and 1999, J. Geophys. Res., 107(D10), 40974109, doi:10.1029/2001JD000536, 2002.

Kasper-Giebl, A., Kalina, M. F., and Puxbaum, H.: Scavenging ratios for sulfate, ammonium and nitrate determined at Mt. Sonnblick (3106 m a.s.1.), Atmos. Environ., 33, 895-906, 1999.

Konishi, H. and Wada, M.: Seasonal variation of clouds and precipitation at Ny-Alesund, arctic, in: Preceeding 28th Symp. Polar Meteorol. Glaciol., Tokyo, Japan, 73-74, 30 November-1 December 2005.

Lehrer, E., Wagenbach, D., and Platt, U.: Aerosol chemical composition during tropospheric ozone depletion at NyAlesund/Svalbard, Tellus, 49B, 486-495, 1997.

Murao, N., Kaneyasu, N., Utiyama, M., Sasaki, H., Ohta, S., Yamagata, S., Kondo, H., and Satoh, H.: Accuracy of trajectory calculations for large-scale air pollution in East Asia, J. Global Environ. Eng., 3, 23-35, 1997.

Murakami, M., Kimura, T., Magono, C., and Kikuchi, K.: Observation of Precipitation Scavenging for Water-Soluble Particles, J. Meteorol. Soc. Jpn., 61, 346-358, 1983.

Nishita, C., Osada, K., Hara, K., Kido, M., Wada, M., Shibata, T., and Iwasaka, Y.: Number-size distributions of atmospheric aerosol particles $(10<\mathrm{Dp}<365 \mathrm{um})$ at $\mathrm{Ny}$-Alesund, Norwegian arctic: Their relationship with air mass history, Polar Meteorol. Glaciol., 15, 67-77, 2001.

Nyeki, S., Coulson, G., Colbeck, I., Eleftheriadis, K., Baltensperger, U., and Beine, H. J.: Overview of aerosol microphysics at arctic sunrise: measurements during the NICE renoxification study, Tellus, 57B, 40-50, 2005.

Ohta, S. and Okita, T.: A chemical characterization of atmospheric aerosol in Sapporo, Atmos. Environ., 24A, 815-822, 1990.

Ohta, S., Fukasawa, T., Muroa, N., and Makarov, V. N.: Summer concentarions of atmospheric pollutants in urban and rural areas of Siberia, J. Global Environ. Eng., 1, 15-26, 1995.

Okita, T., Hara, H., and Fukuzaki, N.: Measurements of atmospheric $\mathrm{SO}_{2}$ and $\mathrm{SO}_{4}^{2-}$, and determination of the wet scavenging coefficient of sulfate aerosols for the winter monsoon season over the sea of Japan, Atmos. Envion., 30, 3733-3739, 1996.

Quinn, P. K., Andrews, B., Christensen, J., Dutton, E., and Shaw, G.: Acidifying Pollutants, arctic haze, and Acidification in the arctic, NSF 05-39, Arctic Research of the United States, 19, 2633, 2005. 
Shaw, G. E. and Khalil, M. A. K: Arctic haze, in: Handbook of Environmental Chemistry, 4/Part B, edited by: Hutzinger, O., Springer-Verlag, Berlin, 1989.

Shaw, G. E.: The arctic haze Phenomenon, Bull. American. Meteorol. Soc., 76, 2403-2413, 1995.

Shiobara, M., Yabuki, M., and Kobayashi, H.: A polar cloud analysis based on micro-pulse lidar measurements at Ny-Alesund, Svalbard and Syowa, Antarctica, Phys. Chem. Earth, 28, 12051212, 2003.

Stroem, J., Umegard, J., Torseth, K., Tunved, P., Hansson, H.-C., Holmen, K., Wismann, V., Herber, A., and Koenig-Langlo, G.: One year of particle size distribution and aerosol chemical composition measurements at the Zeppelin Station, Svalbard, March 2000-March 2001, Phys. Chem. Earth, 28, 1181-1190, 2003.
Teinila, K., Hillamo, R., Kerminen, V.-M., and Beine, H. J.: Chemistry and modal parameters of major ionic aerosol components during the NICE campaigns at two altitudes, Atmos. Environ., 38, 1481-1490, 2004.

Tutiempo.net: http://www.tutiempo.net/en/Climate/ NY-ALESUND/10070.htm, last access: 17 June 2008.

Wada, M. and Igarashi, M.: Atmospheric observations of liquid water in cloud and of chemical species in aerosols and gases near the ground and in fallen snow at Svalbard, Arctic, Atmos. Res., 46, 383-389, 1998.

Wada, M. and Konishi, H.: A study of precipitating clouds close to fronts using microwave radiometry and radar in Svalbard, Arctic, Atmos. Res., 49, 253-265, 1998. 